\title{
INSTITUTIONALISATION ASPECTS IN THE USE OF GEOGRAPHIC INFORMATION SYSTEM (GIS)
}

\author{
Mohd Ramzi Mohd Hussain ${ }^{1 *}$ \\ ${ }^{1}$ Department of Landscape Architecture, KAED, International Islamic University Malaysia (IIUM), 53100 Jln \\ Gombak Kuala Lumpur MALAYSIA \\ *ramzi@iium.edu.my
}

\begin{abstract}
The paper explains the institutionalisation aspects associated with the utilisation of GIS in an organisation. Studies of technology in organisations have demonstrated the value of treating information technologies as human artefacts with social constructed meanings. Simultaneously, the human agency has the potential to revise both the information systems and the social context within which the technology is used. Given these circumstances, this paper focuses on the institutionalisation aspects between individual and organisational factors in utilising GIS. These aspects are important in order to recognise patterns in the way GIS is implemented and used. The study identified five set of institutionalisation aspects that governed the effective use of GIS in organisation. They are the organisational context, the personalities of the individual involved, the impact of change and instability, centralisation and decentralisation of computing technology in organisation and the state of computing development. The paper combines an overview of institutionalisation aspects and their relationship to GIS with examples of strategies adopted by organisations to handle this aspect of system development. The overview provides framework from the subsequent literature concerning the implementation of information technology in general and applying this to the utilisation of GIS. Therefore, the paper provides a more interesting and insightful perspective of the utilisation of information such as GIS in organisations.
\end{abstract}

Keywords: GIS; institutionalisation aspects; technology utilisation

\section{Introduction}

The institutionalisation of information technology such as Geographic Information System (GIS) is a process of embedding the technology in organisation (Alterkawi, 2005; Campbell, 2005; Drummond and French, 2008). Identifying the institutionalisation aspects help to analyse the issues associated with the technology-and-its-social-system. Given these circumstances the institutionalisation aspects particularly the personal/individual and organisational factors are likely to have profound influence on the extent to which the opportunities offered by GIS will be effectively used and practiced. Orlikowksi (2000) argues that the study of information technology belongs as much to the social sciences which insist on the adoption of a critical attitude of users towards implementation and utilisation of information technology. Consequently the study of this kind influences the extent to which opportunities offered by GIS are effectively used and practiced. The structure of this paper is as follows. The first section reviews the institutionalisation aspects which consist of the organisational context, the personalities of the individual involved, the impact of change and instability, centralisation and decentralisation of computing technology in organisation and the state of computing development. These provide the basis for exploring the institutionalisation aspects associated with the implementation of technology. The second and third sections provides the overview of how organisation and individual as the adopters of the information technology. As a result of these evaluations, the fourth section seeks to identify the conditions required for the effective utilisation of GIS in organisations. 


\section{The Institutionalisation of GIS}

The successful use of information technology, such as GIS, in organisations rests with the influences of the individuals, the organisations and the technology itself. As the institutionalisation of GIS is a process embedding the technology-and-its-social system, there is an urgent need to investigate the organisational and individual factors which can be considered and incorporated for the effective use of GIS. Information technology is not only rooted in organisations but has social consequences which depend upon people to use it (Eason, 1998; Henry-Nickie et al., 2008). This suggests that GIS does not produce benefits independently but needs people to exploit its capabilities. It is necessary to ensure that users are both willing and able to use the technology (Henry-Nickie et al., 2008; Drummond and French, 2008). This depends upon their viewing the work they are asked to undertake as worthy of their effort and viewing the technology as a valued and usable tool for undertaking the tasks. The users also determine the way in which a technology is deployed; this use is not inevitable, built into the technology, or fixed (Mackay, 1995; Kallinikos, 2004).

Many researchers have highlighted issues in using information technology such as GIS, which are not only limited by hardware and software but depend largely on how organisational factors and individual users accept and utilise the technology (Reeve and Petch, 1999; Eason, 1993a \& 1993b; Nedovic-Budic, 1997; Yeh, 2005; Batty, 2005; Drummond and French, 2008; Henry-Nickie et al., 2008). Organisational factors can play a significant role in the optimisation of information technology use because they determine how to use the system and the types of tasks performed (Turk, 1993). In this study, the organisational factors include how well the staff of planning department understands GIS and its role, and the ability of the planning organisation to use information technology. Individual aspects include skills, training and GIS knowledge of the planning staff in utilising GIS. They also include the style of leadership of the planning officers, the educational background and staff willingness as well as the ability and capacity to absorb and use GIS in their planning activities. Reeve and Petch (1999) add that human issues, as much as technical ones, determine the success of information technology developments and implementation in organisations. In this situation, the implementation and utilisation of GIS is expanded to include not only the hardware and software but also the individual planning staff involved. However, little consideration has been given to human issues in implementing this technology. As a result, peoples have not fully utilised the technology due to a lack of GIS skills, training and knowledge. Therefore, this study identifies on the individual and organisation factors that affect the successful use of information technology in organisations (Faraj et al., 2004: Budic and Godschalk, 1993; Budic, 1994; Nedovic-Budic, 1999). They focus not only on technology but also on how organisational factors and individual staff in planning organisations react and use the technology (Campbell, 1994; Campbell and Masser, 1995; Yeh, 1991 $\& 2005)$.

According to Campbell and Masser (1995) and Campbell (2005) an understanding of organisations within which GIS is to function is fundamental in order to understand the challenges of development and the use of GIS. Campbell (2005) adds that the use of GIS in organisations is directly tied to the organisational and individual adoptions of the technology. These situations are important in relation to specifying the involvement of individual and organisational factors in understanding the use of information technology in local governments (Reeve and Petch, 1999). In particular, Schwarz (2002) shows that the introduction and use of computing systems can reinforce existing structures of authority, centralised communication and power in organisations. 
Information systems have been shown to maintain existing administrative structures, to centralise control and to enhance power for those already in positions of authority (Schwarz, 2002). Thus, in order to improve the success rate of GIS utilisation, it is clear that attention needs to be paid to understanding the organisational milieu within which GIS is used. Several other researchers have contributed hugely to a better understanding of non-technological parameters influencing GIS implementation and utilisation (Alterkawi, 2005). For instance, the contributions of Ground Truth: The Social Implications of Geographic Information Systems (Pickles, 1995) display a wide set of theoretical reflections on how GIS modifies the perceptions and actions of users. It shows that the emergence of GIS as both a disciplinary practice and a socially embedded technology represents an important change in the way in which the geographical is being conceptualised, represented, and materialised in built environment (Pickles, 2005; Alterkawi, 2005).

This paper discusses a framework from the subsequent literature concerning the institutionalisation of GIS in organisation. The framework suggests there are five sets of institutionalisation aspects that govern the use of computing technology within an organisation. These are the organisational context, the people involved, the impact of change and instability, centralisation and decentralisation of computing technology in organisation and the state of computing development. They are:

\author{
i. The Organisational Context; \\ ii. The People; \\ iii. The Change and Instability; \\ iv. The Centralisation and Decentralisation; and \\ v. The State of Computer-based Development.
}

Evidence from this work indicates that these factors are likely to have a decisive influence on both the initial decision to adopt a technology such as GIS and the subsequent process of implementation and utilisation. Each of these will be discussed next.

\title{
2.1 The Organisational context
}

The first set of factors emphasizes the organisational context in which GIS technology is implemented. Studies which focus on computer equipment propose that the nature of the technology determines the outcome of the implementation process (Nedovic-Budic, 1997; Campbell, 2005). This suggests that the experiences of planning organisations are significantly influenced by the organisational context and dealings between individual planning staff. This section examines the contribution of the organisational context to the evolution and utilisation of information systems, particularly GIS, in planning organisations. This contextual factor is subdivided into two levels; the internal organisational context and the external environment. Together, they provide the background against which computer usage takes place (Nedovic-Budic, 1997). The external environment include the availability of independent sources for funding, the authority's population size and individual per capita income while the internal environment include the presence of a professional chief executive and the location of control over computing decisions. 
The internal organisational context relates to the characteristics of the planning organisation in which the computer-based system is located. These include features such as the organisational structure, administrative arrangements and procedures for decision-making in general and, specifically, with regard to computing resources. Many organisations are sub-divided into many sections (Nedovic-Budic, 1997). This means that the adoption and subsequent implementation of GIS in planning organisations is not simply embedded within one context but must also take into account of the individual characteristics of each unit. The diverse range of environments in each of this unit is therefore likely to inhibit the implementation process of GIS in the planning organisations. This in turn has implications for the succeeding implementation and utilisation of the systems.

The existing administrative arrangements may also hamper the introduction of new technology while the potential of a system, such as GIS, to enhance accessibility to information is likely to be viewed with suspicion as it opens up the decision-making process of individual units to greater scrutiny (Masser and Campbell, 1992 \& 1995; Nedovic-Budic, 1997; Campbell, 2005). Consequently, each departmental unit may refuse to allocate information systems resources to such a project or, at a later stage, prove unwilling to agree on standards or share data. Thus, Nedovic-Budic (1997) states that there is a need to motivate each departmental unit for incorporating GIS, with a recognised gap in organisational performance as the most common motivation behind organisational engagement in adoption of innovations.

Features of the external environment also influence the utilisation process of information technology in organisations (Masser and Campbell, 1991 \& 1995; Nedovic-Budic, 1997). Computer manufacturers and suppliers obviously have a significant role to play, particularly in terms of their research, development and marketing strategies as well as their posts-sales support and training programmes. However, a number of agencies can also influence the pace of GIS adoption and the effectiveness of its implementation. These include other organisations in the same field, central governments, professional opinions and, perhaps, even trends in society. These elements provide the personal and more general communication channels through which knowledge of new developments and opinions as to their value are transferred. The skills of staff may also influence the effective use and implementation of a technology such as GIS.

Consequently, the internal and the external environments of the planning organisations provide the background against which the implementation of GIS is embedded. The detailed nature of the key characteristics varies between planning organisations but the underlying concept remains useful. The emphasis placed on the influence of contextual factors should not, however, be assumed to suggest rigid determinism as these elements interact with the individuals present within planning organisations. It is noted that these characteristics are either associated with the context or the activities of individual members of planning staff in local authority planning departments. This demonstrates the contribution of the internal and external planning organisational context to the implementation of computer-based information system. For instance, it cannot be presumed that a large planning organisation is automatically an extensive computer user or that a small planning organisation has little experience of automation. 


\subsection{The People}

The context of the planning organisation and the operation of political processes in the planning organisation have a substantial impact on the outcome of computerisation. However, there is also a need to consider the activities and characteristics of the individuals. Thus, this section explores the contributions of individual planning staff to the adoption, implementation and utilisation of GIS in planning organisations. The activity of individual planning staff can substantially affect the development and utilisation of computer-based systems. It is emphasised that the individual staff within planning organisations have different values and motivations, and that computerisation tends to challenge their interests; threatening some and offering opportunities to others. This suggests that individual planning staff can perform an important role in the process of GIS implementation in planning organisations. It is also important that the role played by the planning staff includes the necessary ability, willingness and awareness to implement and use GIS in the planning organisation. Furthermore, it is unlikely that the goals of the planning staff necessarily coincide with those of the planning organisation in which they work.

In many instances, the benefits from the introduction of GIS in planning organisations are perceived by some individual staff as a threat and others as an opportunity. It is likely that the bargaining over the control and distribution of benefits associated with the introduction of a computer-based system will take place at a corporate level, within separate sections and, where appropriate, between agencies (Masser and Campbell, 1991 \& 1995). Key individuals often play an important role in both the initial acquisition of new technology and the subsequent processes of achieving effective utilisation (Kraemer and Dedrick, 1997; Kraemer and Norris, 1993). This means that the purchasing of GIS by the planning organisations is frequently associated with the awareness and readiness of the individual users of the planning staff. Consequently, each planning staff must possess the necessary ability, willingness and intimate knowledge to implement and use GIS successfully (Masser and Campbell, $1991 \&$ 1995).

Generally, interest in GIS is not confined to individuals most directly involved within the planning organisations. Staff throughout the planning organisations also has to play a role or be concerned with the implication of new technology (Masser and Campbell, 1995; Campbell, 2005). Sometimes, they may be opposed to, it because their past experiences with computer technology were not entirely favourable. These issues are especially important in relation to the implementation and utilisation of technology such as GIS. The activities of planning officers in using GIS help to encourage other planning staff to use GIS. These include their contributions in acquiring GIS skills, training and knowledge towards the institutionalisation of GIS in planning organisations. In addition, the awareness and encouragement given to other planning staff to use GIS also play an important role which can determine whether the system is actually used. These individuals are likely to be members of the senior management in planning organisations as they are most closely involved with the committees which are responsible for budgeting although, in certain circumstances, a middle ranking officer may be able to take the initiative (Masser and Campbell, 1995; Campbell, 2005). For example, the role played by the Planning Director or the Head of Department concerning the distribution of GIS within the planning organisation is pivotal in ensuring the effective use of GIS. However, a lack of mutual understanding between them and computer experts can affect the development of GIS in the planning organisation. Failure on this part can lead to wasted and redundant resources of technology in the planning organisation. 
The interpersonal relationships between the users and the technical specialists have a significant impact on the development of information system (Masser and Campbell, 1995; Campbell, 2005; Yeh, 2005). This means that some planning staff with computer knowledge and skill in the planning organisation tends to be more interested in the design of GIS. As experts, they become involved in the implementation and utilisation processes of GIS in the planning organisation. They are more likely to act in accord with their perceptions of what the planning staff regards as desirable so as to avoid harming their career prospects. It is assumed that the introduction of computer-based systems changes work experience by altering the work environment and the nature of job skills, and affecting the quality of social interaction within the organisation (Campbell, 2005; Yeh, 2005). This suggests that the introduction of GIS in planning organisations has both positive (job satisfaction and interest in their work) and negative effects (level of stress and pressure) on individual planning staff. However, the negative effect, which is the level of stress and pressure among planning staff, is seen as less important in local planning authorities in Malaysia as more planning staff become familiar with the use of GIS.

It has been discovered that some of individual staff within an organisation are not active in implementing and utilising information technology (Campbell, $1992 \&$ 1994). This is because some of the staff was naturally suspicious and cautious about the introduction of GIS in their organisation (Campbell, 1994). They generally prefer to use the existing method rather than changing to GIS. Some of them are afraid of the new computing technology which could slow their progress and also requires them to learn new technology. Thus, in order to avoid these situations, they chose to avoid from actively participating in the technology. This means that, in order to use GIS effectively in planning organisations, each individual planning staff must be aware of and acknowledge the technology before they become involved and utilise it.

However, it is not only the middle and lower levels of staff that may be sceptical towards change involving new technology (Campbell, 1992 \& 1994). Members of the senior management can also be negative towards computerisation; being wary of the challenge to their power and control from a technology which offers an apparently more 'rational' although not fully understood mode of decision-making (Campbell, 1994). This negative response may be perceived as honest resistance to a misguided system. Consequently, all levels of staff within planning organisations starting from the managerial position have to understand what GIS is, how GIS can be implemented in planning organisations and what level of skills and training which the lower, middle and officer have to acquire. This suggests that the planning director must have a strategy to successfully implement and use GIS.

Although there have been strong commitments of staff to the implementation of GIS in organisations, the presence of technology provides no guarantee that it will be used by all staff (Campbell, 1994; Kraemer and Dedrick, 1997). It would appear that the characteristics of individuals and the interaction between personalities play an important role in ensuring the utilization of technology. The personnel within organisations possess very different skills and views of the type of activities for which information systems are useful as well as differences in their willingness and inclination to use technology (Kraemer and Dedrick, 1997). This means that the continuation of GIS awareness, skills, and knowledge from the implementation stage must continue to the utilisation stage. These steps help the planning staff to use GIS continuously.

Furthermore, the tendency to utilise information technology has been linked to personal characteristics such as age, sex, length of time spent in the same job, educational qualification, membership of professional body and training or experience in computer-related field (Kraemer and Dedrick, 1997). Kraemer and Dedrick 
(1997) state factors such as computing skills and experiences of working with computer support the significance and the degree of confidence of the end-users. This suggests that the successful use of GIS is associated with the personal characteristics of the planning staff in the departments. For example, the training and experience in computer-related skill helps the planning staff to easily understand and use GIS smoothly.

The impact of GIS on planning organisations is significantly influenced by individual planning staff. The relationship between the individual planning staff characteristics and the staff personality also affects GIS usage in planning organisations. The outcome of GIS is therefore influenced by a complex set of interacting factors but these conditions are not static as the third element seeks to demonstrate.

\subsection{The Change and Instability}

The third set of elements is the impact of change and instability. It must be noted that no organisation is static (Campbell, 2005). A highly volatile technical, social or political environment is liable to impede the effective development and utilisation of automated systems (Campbell, 1994; Campbell and Masser, 1995). This means that the degree of instability present within a planning organisation as well as the level of change in the external environment have an important influence on the implementation and adoption of GIS. Changes in the organisational structure and consequent shifts in the paths of information flow are therefore fundamental disruptions in the functioning of the organisation and are justifiably interpreted as threats to the organisation itself (Campbell and Masser, 1995).

The changes in position within an organisation cause changes in the balance of power among units (Campbell, 1994). This view shows that the position held by planning directors and heads of planning departments which keep changing over the years could affect the process of implementing and utilising GIS in planning organisations. The decision by them to introduce technology or modify an existing system is usually prompted by some changes in the organisational context. Therefore, the redistribution of, and access to, information through the introduction of an automated information system can also lead to the redistribution of power and influence (Campbell, 1994; Campbell and Masser, 1995). Consequently, the impact of instability on the implementation and use of GIS in planning organisations appears to be complex. Instability is a critical factor in understanding difficulties faced by organisations (Campbell, 1994; Masser and Campbell, 1994; Campbell and Masser, 1995). This suggests that the implementation of GIS in planning organisations is not designed once and for all. This is due to changing circumstances such as alterations to the format for statutory returns which require modifications to be made (Campbell, 1994; Masser and Campbell, 1994). Therefore, the implementation and utilisation of GIS in planning organisations is an ad hoc and incremental process with amendments to existing systems in the organisation. Computer-based systems prosper in stable conditions where there is a steady flow of resources to maintain routine procedures (Campbell, 1994).

Moreover, the development and subsequent maintenance of systems are also likely to be affected by modifications to, for instance, an organisation's internal structure of the resignation of key personnel (Campbell, 1994; Masser, 1998). The latter in particular can have a very profound impact as new working relationships have to be developed while considerable experience and knowledge may be lost. All organisations face a measure of instability but, in certain instances, the degree of volatility is such as to either inhibit resources being made available for the introduction of technology or to disrupt the implementation and utilisation of an existing 
system (Masser and Campbell, $1991 \&$ 1995). This suggests that change is not just limited to the nature of the available technology but is an inherent part of the context in which the activities of the organisations are embedded.

\subsection{The Centralisation and Decentralisation}

The fourth set of element is centralisation and decentralisation of computer-based information systems in organisation. According to Kraemer and Dedrick (1997) the centralisation and decentralisation of computerbased information systems in organisations are important in order to encourage end-users to adopt information technology. They add that the introduction of personal computers (PC) and client-server computing based on standard software packages has encouraged the argument for decentralised computing. Although the size and cost of mainframe computers argue for centralisation of the computing function, PC technologies make it feasible to break that function into smaller departmental units. This suggests that the decentralisation of GIS in planning organisations is undertaken by putting the GIS package under the direct control of end-users (planning staff). The end-users are responsible for helping planning organisations to tailor GIS according to departmental needs and objectives.

On the other hand, the centralisation of GIS in planning organisations is believed to increase the economics of scale in procurement, enhance data sharing within the planning organisations and ease planning director/s and head of department/s ability to guide computing toward department wide-goals. The case for centralisation has been based on notions of efficiency in the information systems function itself rather than on enhancing the end-users' access to and control over information technology (Kraemer and Dedrick, 1997). However, despite the trend toward decentralisation, most organisations continue to have a central computing unit and, in recent years, the trend seems to be swinging back toward centralisation as a way to get some control over the proliferation of often incompatible end-user technologies in organisations. Whether computing is centralised or decentralised, this is indeed a critical issue. Some argue that centralisation of managerial control rather than facilities and services is the key factor. However, it is frequently the case that control follows the location of facilities and services. That is, the tendency is for managerial control to be centralised when facilities and services are centralised and become decentralised when facilities and services are decentralised. These views suggest that there are instances involving a mix of centralisation and decentralisation of utilisation of technology such as GIS in organisations; for example, centralising the unit of GIS for each department but decentralising the facilities and services.

An organisation that wishes to decentralise can implement information systems that provide necessary information to lower-level officers and permit top management to communicate with those officers. However, in organisations where both are centralised, computing is likely to be used by senior officers in order to substitute technology for middle management functions, such as information processing communication. On the other hand, in organisations where both are decentralised, computing is likely to be used by middle officers in order to enhance their values to the senior management and increase, or at least, retain their numbers. These scenarios highlight the appropriateness of the concept of technical determinism which assumes that the theoretical capabilities of technology will be achieved in practice. These suggest that the result of 
computerisation reflect the underlying aims of the senior staff. Therefore, the introduction of automated systems produces; for example, centralised decision-making on its own.

\subsection{State of Computer-based Development}

The final set of element is the state of computer-based development in organisation. It is clear that the key determinant of organisations in the implementation and utilisation of subsequent technology such as GIS involves the ability of organisations to tailor information technology according to their needs and characteristics. Kraemer et al., (1995) argue that computing can be characterised by various states of development and these states determine the effectiveness of computing within the organisation. Three pure states are identified, namely skill, service, and control while the fourth consists of a mixed state.

In the skill state, information system management controls computerisation and applies computing resources to technical interests (Kraemer and Dedrick, 1997). In the service state, the departmental management controls computing, and the operational interests of the department are served. In the control state, the senior management controls the computerisation, and its broad managerial interests are served. A mixed state exists in the absence of any of the three pure states. That is, the mixed state encompasses any set of conditions in which the level of control and the level of interests served do not directly correspond.

These perspectives suggest that the implementation and utilisation of GIS in the planning organisations are based on three states as identified above. They focus on the management action, whether direct or indirect, as the controllable driver of computer-based implementation and utilisation. It also permits the identification of the current state of GIS in planning organisations as well as the prediction of future trajectory of computing. Moreover, it shows how the trajectory of computing is governed by the management action of the planning organisations.

\section{i) The Nature of Computing Technology}

Assumptions concerning the nature of computing technology are fundamental in order to understand the issues involved in the implementation and use of computer-based systems in planning organisations. Computing is characterised by many layers of activity; each developing and evolving different manifestations of digital technology (Batty, 2005). Technology, including computerisation, implies the processes and methods that organisations use to accomplish its substantive goals (Nedovic-Budic, 1997).

New information technology such as computer-based system, offers exciting opportunities to improve understanding and practice, to develop and refine theory, and to increase the effectiveness of urban and regional planning (Batty, 1991). Batty (1991) adds that information technology is useful for the planning activities which affect what planners plan, how planners plan, who plans, and is set against the wider context of why planners plan. Computing technology provides a means to carry out routine tasks with speed, precision, and flexibility that are often not easy for the layperson to grasp (Alterkawi, 2005; Batty, 2005; Campbell, 2005; Bracken and Webster, 1990). Longley et al., (2005) argue that the developments in computer technology have been a major contributor to the rapid advances of GIS. This suggests that, in exploring the world of GIS, it is appropriate to begin by charting the main relevant technological advances of recent years and seeking to gauge their impact on GIS. 
The computing technology is not perceived to be isolated from the rest of the organisation or broader external forces; rather it is viewed as embedded within the complex social system of an individual concern. Consequently, the root that cause of all technological advances, as far as GIS is concerned, is improvement in computer hardware. This suggests that the introduction of GIS in planning organisations is embedded between the planning staff within the organisation. The nature of this contextual factor affecting the computing technology in planning organisations is considered later in this chapter. The important issues at this stage are to distinguish studies which concentrate on computer equipment which assumes computing technology to consist of a broader range of variables.

\section{Organisations as Adopters of Information Technology}

This section discusses organisations as adopters of information technology, in particular GIS. As discussed above, the adoption of information technology is shaped by organisational issues. The term 'adoption' is often used in general diffusion research to identify utilisation of an innovation. Consequently, the word 'adoption' is defined as the successful use of GIS. This suggests innovation processes in planning organisations are usually considered if it leads to the adoption, including routinisation of new ideas and not just to the adoption decision per se.

The adoption of new information technology in the workplace has become a transition experience common to most organisations (Nedovic-Budic and Godschalk, 1996). The success of these endeavours depends as much upon the nature of the individual staff within the planning organisation as on the technology itself. Nedovic-Budic and Godschalk (1996) define organisational adoption as the use of the technology for performing organisational tasks; that is, its internalisation into organisational processes and functions. Thus, the complex nature of planning organisations as adopters of new technologies poses a challenge to the implementation of information technology such as GIS. This means that the incorporation of new technology such as GIS in planning organisations is a reciprocal/mutual process: organisational characteristics influence diffusion of the computing innovation, and the innovation in turn influences the planning organisation.

Huxhold and Levinsohn (1995) propose that organisations adopt information technology because they anticipate it will provide new capabilities that will yield benefits to the organisation. Building on this assumption, there are four elements that the planning organisation must consider in order to adopt GIS. They are the GIS paradigm, data management principles, technology, and the organisational setting. A GIS paradigm is the conceptual foundation for using geographic information that provides a common base of reference or focus for the other three elements. Data management principles govern the logical structuring and management of large databases that contain maps and other data that can be related to the geography of interest to the organisation. Technology comprises the effective combination of various hardware and software components that enable the automation of numerous geographic data handling functions. Finally, the organisational setting implies the management environment that provides resources and enables changes to be made for incorporating GIS utilisation throughout the planning organisation. 


\section{Individuals as Adopters of Information Technology}

The above section describes the importance of organisations as adopters of information technology such as GIS. This section, on the other hand discusses the role played by individuals as users of GIS. It has been assumed by researchers that individual users are the ultimate and most important adopters of information technology, such as GIS, among many possible users namely organisations, organisational units and organisational sub-units (Nedovic-Budic and Godschalk, 1996; Budic and Godschalk, 1994; Rogers, 1993; Masser and Campbell, 1991 \& 1995; Nedovic-Budic, 1997; Campbell, 2005). This view suggests that the individual staff in planning organisations plays an active, creative role in the innovation process by matching the innovation with a perceived organisational problem and, perhaps, in re-inventing the innovation. An innovation should not be conceived as a fixed, invariant, and static element in the innovation process but as a flexible and adaptable idea that is consecutively defined and redefined as the innovation process gradually unfolds; often leading to re-invention (Nedovic-Budic, 1997; Campbell, 2005). Consequently, the characteristics of an innovation as perceived by the individual staff in the planning organisation determine the rate of GIS adoption.

After GIS is acquired by planning organisations, decisions on its use are made by or for each employee individually. These individuals may either volunteer or be assigned to work with GIS. Their understanding as well as their relationship with GIS has been shown to be critical. This means that the introduction of GIS tends to challenge the individual traditional interests; threatening some and offering opportunities to others.

\section{Conditions for the Effective Use of GIS}

Based on the nature of technology and the likely impact of institutionalisation aspects on the implementation of GIS, this section seeks to introduce a more prescriptive element into the discussion. A number of studies based on examining a range of computer applications have sought to provide guidance to users. The findings of these studies are largely summarised five necessary and generally sufficient conditions for the effective adoption and utilisation of GIS (Masser and Campbell, 1991; 1995; Nedovic-Budic, 1997; Kraemer et al., 1995; Campbell, 2005; Yeh, 2005). These five conditions are outlined below:

- The existence of an overall information management strategy based on the needs of users and the resources available within the organisation such as staff skills;

- The personnel commitment and participation of individuals at all levels of the organisation;

- A high degree of organisational stability with respect to personnel, administrative structures and environmental considerations;

- The political power and control of the organisation to centralise or decentralise or both in the adoption, implementation and utilisation of information technology;

- The states of ability of the organisations to tailor the information technology to their needs and characteristics.

The likely impact of institutionalisation aspects on the utilisation of GIS is marked when one considers applying the above conditions to a multi-user environment. 
The development of an information strategy is crucial organisations are to avoid a mismatch between the information required by users and the data generated. Effective utilisation, however, depends on the existence of an overall information management strategy in each of the organisational units involved which in turn, assumes general agreement or priorities and the resources to be devoted to the project. The second condition emphasizes the importance of involving and gaining the commitment of staff at all levels and in all the participating organisations. Users have a critical role as they have the fullest appreciation of their context and needs and as a result it is important they are placed at the centre of the process. The third condition suggests the need to have a high degree of organisational and individual stability to cope with the management of change which is associated with the introduction of new technology. In the case of multi-user system the instability of even one organisation is likely to cause sufficient uncertainty to threaten the success of the whole operation. The fourth condition suggests the political power and control within the organisation is important aspects of information technology utilisation. It assumes that if the information is power, then centralised computing concentrates power at high levels in the organisation, while decentralised computing devolves more power to subunits within the organisation. The final condition suggests more focuses should be taken on management action, direct or indirect as the controllable of computing implementation and utilisation. This is crucial as to identify the currents needs as well as the future needs of computing in organisation.

\section{Conclusion}

The overview provides a general framework for the consideration of the nature of institutionalisation aspects and the conditions which are necessary for the effective adoption and utilisation of GIS. The recognition that individuals are knowledgeable and skilful is a central premise of this process. Skills refer to the capacity of individual user to routinely understand what they are doing while they are learning to use the technology. The knowledge and skills, however, are always bounded to some extent by the situated nature of action, the difficulty of articulating tacit knowledge, unconscious sources of motivation, and unintended consequences of action. Given this framework the subsequent case studies is needed to examine a number of organisational and individual approaches which attempt to satisfy these conditions.

\section{References}

Alterkawi, M.M. (2005). Measures Towards a Comprehensive Municipal GIS -the case of Ar-Riyardh Minucipality. Habitat International, 29, 689-698. Elsevier Ltd.

Batty, M. (1991). New Technology and Planning: Reflections on Rapid Change and the Culture of Planning in the Post-Industrial Age. Town Planning Review, Vol. 62, No.3, 269-294. Liverpool University Press.

Batty, M. (2005). New Technology and GIS. In Longley, P.A., Goodchild, M.F., Maguire, D.J. and Rhind, D.W. (Eds.). Geographical Information Systems (Second Edition). Principles, Techniques, Management, and Applications. (pp.309-316). John Wiley \& Sons, Inc.

Bracken, I., and Webster, C. (1990). Information Technology in Geography and Planning: Including Principles of GIS. London and New York: Routledge. 
Budic, Z.D. (1994). Effectiveness of Geographic Information Systems in Local Planning. Journal of American Planning Association, Vol. 60, No. 2, 244-263.

Budic, Z.D., and Godschalk, D.R. (1994). Implementation And Management Effectiveness In Adoption Of GIS Technology In Local Governments. Computers, Environment and Urban Systems. Vol. 18, No. 5, $285-$ 304. Elsevier Science Ltd.

Campbell, H.J. (2005). Institutional Consequences of the use of GIS. In Longley, P.A., Goodchild, M.F., Maguire, D.J. and Rhind, D.W. (Ed.). Geographical Information Systems (Second Edition). Principles, Techniques, Management, and Applications. (pp.621-631). John Wiley \& Sons, Inc.

Campbell, H. (1992). Organizational and Managerial Issues in Using GIS. In Cadoux-Hudson, J., and Heywood, I.D. (Eds.). The Yearbook of the Association for Geographic Information: Geographic Information 1992/93. (pp. 337-344). Taylor \& Francis.

Campbell. H. (1994). How Effective are GIS in Practice? A Case Study of British Local Government. International Journal of Geographic Information Systems, Vol. 8, No. 3, 309-325. Taylor \& Francis Ltd.

Campbell, H., and Masser, I., (1995). GIS and Organizations: How Effective are GIS in Practice? Taylor Francis Ltd.

Drummond, W.J. and French, S.P. (2008). The future of GIS in Planning: Converging Technologies and Diverging Interests. Journal of the American Planning Association. Vol. 74, Issue 2, 161-174.

Eason, K.D. (1993a). "Planning for Change: Introducing a Geographical Information System." In MedyckyjScott, D., and Hearnshaw, H.M. (Eds.). Human Factors in Geographical In formation Systems, (pp. 199210). London: Belhaven Press.

Eason, K.D. (1993b). "Gaining User and Organizational Acceptance for Advanced Information Systems." In Masser, I., and Onsrud, H.J. (Eds.). Diffusion and Use of Geographic Information Technologies, (pp. 2744). Kluwer Academic Publishers.

Eason, K.D. (1998). Information Technology and Organizational Change. Taylor \& Francis.

Faraj, S., Kwon, D., and Watts, S. (2004). Contested Artifact: Technology Sensemaking, Actor Networks, and The Shaping of The Web Browser. Information Technology \& People, Vol. 17 No. 2, 186-209. Emerald Group Publishing Limited.

Henry-Nickie, M., Kurban, H., Green, R.D., and Phoenix, J.A. (2008). Levelling the Playing Field: Enabling Community-Based Organisations to Utilize Geographic Information Systems for Effective Advocacy. URISA Journal. Vol. 20, No. 2. 33-41.

Huxhold, W.E., and Levinsohn, A.G. (1995). Managing Geographic Information System Projects. Oxford: Oxford University Press.

Kallinikos, J. (2004). Farewell to Constructivism: Technology and Context-Embedded Action. In Avgerou, C., Ciborra, C., and Land, F. (Ed.). The Social Study of Information and Communication Technology: Innovations, Actors, and Contexts. (p.140-161). Oxford: Oxford University Press.

Kraemer, K.L., and Norris, D.F. (1993). Computers in Local Government. CRITO, Graduate School of Management, Uni. Of California, Irvine.

Kraemer, K.L., Dedrick, J., and King, J.L. (1995). The Impact of Information Technology on City Government in the United States. CRITO. Toulouse Conference Paper. 
Kraemer, K.L. and Dedrick, J. (1997). Computing and Public Organizations. Journal of Public Administration Research and Theory. J-PART, Vol. 7, No. 1, 89-112.

Longley, P.A., Goodchild, M.F., Maguire, D.J. and Rhind, D.W. (Eds.) (2005). Geographical Information Systems (Second Edition). Principles, Techniques, Management, and Applications. (pp.309-316). John Wiley \& Sons, Inc.

Mackay, H. (1995). Theorising the IT/Society Relationship. In Heap, N., Thomas, R., Einon, G., Mason, R., and Mackay, H. (Eds.). Information Technology and Society. (pp. 41-53). Sage Publications Ltd. In Association with the Open University.

Masser, I., and Campbell, H. (1991). Conditions for the Effectiveness Utilisation of Computer in Urban Planning in Developing Countries. Computers, Environment, and Urban Systems, Vol. 15, 55-67. Pergamon Press Plc.

Masser, I., and Campbell, H. (1995). Information Sharing: The Effects of GIS on British Local Government. In Onsrud, H.J. and Rushton, G. (Eds.) Sharing Geographic Information. (pp. 230-251). Rutgers, The State University of New Jersey.

Masser, I. (1998). The First Generation of National Geographic Information Strategies. Retrieved on October 22, 2004, from http://www.gsdi.org/docs1998/canberra/masser.html

Nedovic-Budic, Z., and Godschalk, D.R. (1996). Human Factors in Adoption of Geographic Information Systems: A Local Government Case Study. Public Administration Review, Vol. 56, No 6, 554-567.

Nedovic-Budic, Z. (1997). GIS Technology and Organizational Context: Interaction and Adaptation. In Craglia, M., and Couclelis, H. (Eds.). Geographic Information Research- Bridging the Atlantic. (pp. 165-184). London: Taylor and Francis.

Nedovic-Budic, Z. (1999). Evaluating the Effects of GIS Technology: Review of Methods. Journal of Planning Literature, Vol. 13, No. 3, 284-295. Sage Publications, Inc.

Orlikowksi, W.J. (2000). Using Technology and Constituting Structures: A Practice Lens for Studying Technology in Organizations. Organization Science, Vol. 11, No. 4, 404-428.

Pickles, J. (1995). Representations in an Electronic Age: Geography, GIS, and Democracy. In Pickles, J. (Eds.). Ground Truth: The Social Implications of Geographic Information Systems. New York and London: The Guilford Press.

Pickles, J. (2005). Arguments, Debates, and Dialogues: The GIS-Social theory debate and the concern for alternatives. In Longley, P.A., Goodchild, M.F., Maguire, D.J. and Rhind, D.W. (Eds.). Geographical Information Systems (Second Edition). Principles, Techniques, Management, and Applications. (pp. 4960). John Wiley \& Sons, Inc.

Reeve, D.E., and Petch, J.R. (1999). GIS Organizations and People: A Socio-technical Approach. Taylor and Francis.

Rogers, E.M. (1993). The Diffusion of Innovations Model. In Masser, I., and Onsrud, H.J. (Eds.). Diffusion and Use of Geographical Information Technologies. (pp. 9-24). Kluwer Academic Publishers.

Schwarz, G.M. (2002). Organizational Hierarchy Adaptation and Information Technology. Information and Organization, Vol. 12, 153-182. Elsevier Science Ltd. 
Turk, A (1993). The Relevance of Human Factors to Geographical Information Systems. In Medyckyj-Scott, D., and Hearnshaw, H.M. (Eds.). Human Factors in Geographical In formation Systems. (pp. 15-32). London: Belhaven Press.

Yeh, A.G-O. (1991). The Development and Applications of Geography Information Systems for Urban and Regional Planning in the Developing Countries. International Journal of Geographical Information Systems. Vol.5. No.1, 5-27.

Yeh, A. G-O. (2005). Urban Planning and GIS. In Longley, P.A., Goodchild, M.F., Maguire, D.J. and Rhind, D.W. (Eds.). Geographical Information Systems (Second Edition). Principles, Techniques, Management, and Applications. (pp.877-888). John Wiley \& Sons, Inc. 